\title{
Prolonging the Durability and Conservation of Historic Materials by Microclimatic Monitoring in the Archaeological Areas
}

\author{
Elisabetta Rosina and Alessandra Pili \\ Politecnico di Milano, ABC Dept. Piazza Leonardo da Vinci 32, 20133 Milano; email \\ elisabetta.rosina@polimi.it, alessandra.pili@polimi.it
}

\begin{abstract}
Many factors have to be considered for the correct conservation of cultural heritage, in particular, the exposition of the object/site to open air, as the archaeological sites have. The risk factors can be intrinsic (durability of materials, construction and decorative techniques) and extrinsic (environmental and microclimatic conditions). The consideration of the conservation issue regarding the second has to take into account the effects the microclimatic parameters on the objects and the variation of microclimate for the use, as well as the modification due to the improvement of accessibility, safety and installations (for example plant and architecture addition/modification). In fact, the main objective of the conservation/fruition of the archaeological areas is achieving the project choices most integrated, functional and adequate to meet the needs of conservation. Monitoring and diagnostics are a necessary condition to be able to correctly define the design choices. The proposed contribution aims to specify how monitoring the microclimatic values play a fundamental role in the whole process of conservation, since the early study to the management of the site, to ensure the greater conservation and durability of the material and, ultimately, the best fruition at present and in the future.
\end{abstract}

Keywords: Archaeological Site, Historic Materials, Roman Tombs, Accessibility, Durability, Management Plan.

\section{Introduction}

The valorization of cultural heritage, achieved together with the conservation goals, must take into account the control of the condition of use.

The valorization of the wide range of types of cultural heritage includes many different possible uses, always respectful of the compatibility with the cultural goods and sites. In all the cases, the proper management of cultural heritage includes the conscious use(SanchezMoral, 2005), and it is a warrant the conservation: the use is opposed to abandonment, that causes consequently to the loss of historical material, due to the natural effects of aging, waste, human activities etc.

The final goal is to achieve an integrated design that manages to coexist the architectural and plant engineering aspects with the cultural value that the site represents.

In the case of archaeological sites, it is evident that re-use is not functional as it is in historical buildings (Thompson, 2007); however, valorization activities include the correct management of the site, for achieving the conservation goals and economic sustainability.

The Conservation Plan, defined in the cultural heritage code as the tool of the conservation process, includes information related to the constant control of the asset; among these, the code lists diagnostics and instrumental monitoring. 

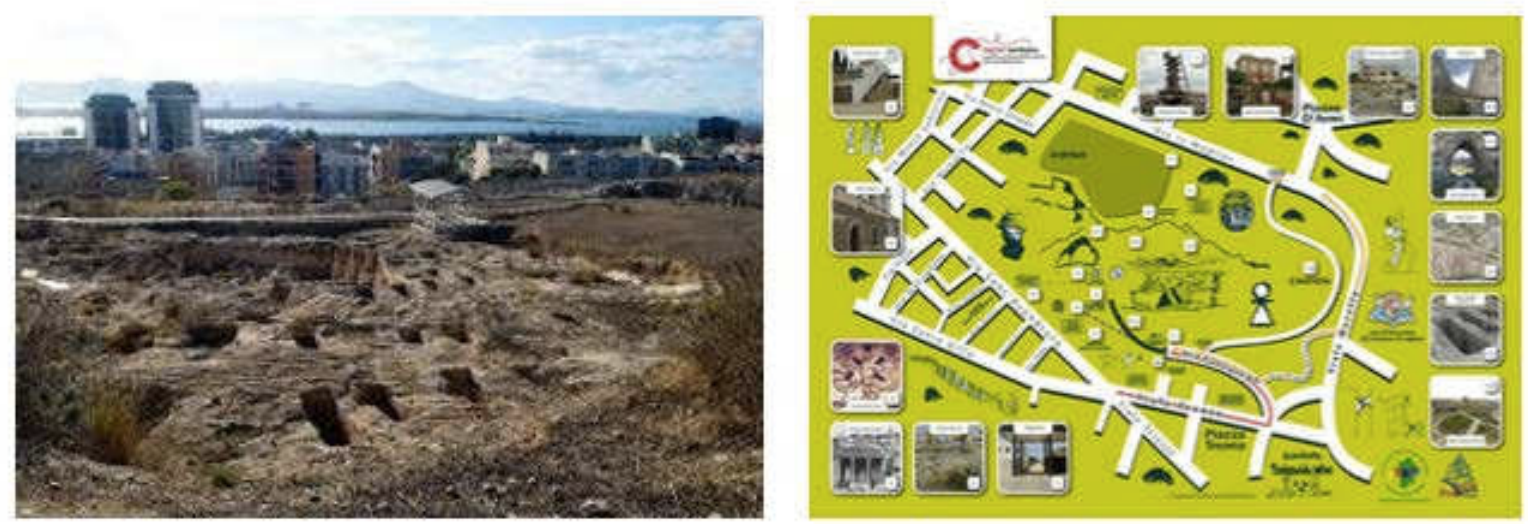

Figure 1 and 2. Aerial view of the archaeological area of Tuvixeddu in Cagliari and sign of the paths and open tombs at the park entrance (credits to Intercral Ass.).

The different complexity of the archaeological sites, compared to other cultural assets, requires to articulate the design to solve the specific problems, above all the mitigation of the effects of the environment and the context (Huisman et al., 2009) including also how the site is used. In fact, the estimation of risks necessarily includes the evaluation of the impact of visitor presence on microclimatic conditions and therefore on the conservation of historical materials: together wit more modifications underground or if it ageing, weathering, passage/nesting of animals toc

Therefore, in the pro
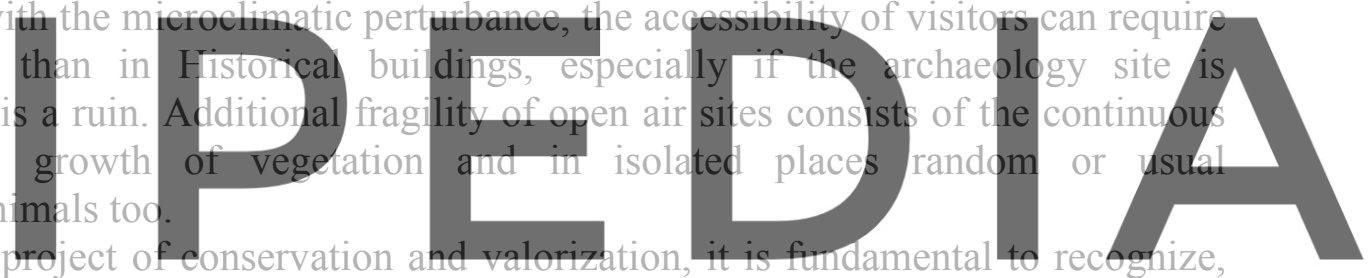

know and understand these factors and the interferences they can generate. Diagnostics and

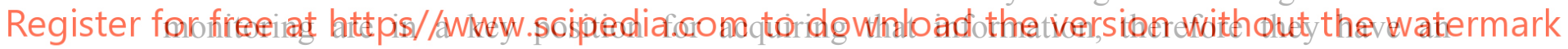

important role in the design and management of sites.

The biggest challenge, still ongoing, is to find an optimal threshold between conservation and valorization. The contribution presented here aims to understand the role of diagnostics and microclimatic monitoring within the cognitive process, both in the preliminary and fruition phases. The final goal is to prolong the durability of the materials, assuming that the material is the manifestation of cultural and historical value. Diagnostics and monitoring are therefore a fundamental activity for understanding and mitigating risk factors that affects the durability of goods and sites (Rosina et al., 2011; Cecchini, 2012; Rosina, 2012; Camuffo et al., 2015; Rosina et al., 2019). In the following, the paper presents the investigation, monitoring, management of an underground Roman tomb in the Necropolis of Tuvixeddu in Cagliari (Figures 1 and 2).

The tomb is built inside a limestone bench and the internal surfaces are decorated with wall paintings and lime mortar stuccos.The assessment of the site regarded materials (surface sampling and chemical analysis for the characterization), degradation (sampling and chemical and biological investigations), archaeological (excavation and acquisition of results), environmental and microclimatic. The latter, which began in July 2017, includes continuous monitoring of microclimatic values (still in progress) and various psychrometric and 
thermographic campaigns with the aim to understand the behaviour of the microclimate at static conditions, how it varies during the seasons, the effects of opening and presence of visitors inside it. Regarding this last aspect, continuous monitoring has allowed the recording and analysis of data also during the phases of archaeological excavation and restoration of the surfaces, when up to 10 people remained inside for many hours a day. The monitoring lasted during the discovery of new burial environments and the lowering of the walking surface to the original height, that changed of the air volume. The measurement made it possible to verify the trend of the microclimatic parameters as the volumetric conditions changed, as well as the variations due to the ventilation conditions and the presence of people.

The microclimatic data were cross-checked with the results of the chemical and biological analyses, that supported also the choice for design and size of the light system (type, lighting localization and time), air conditioning and control to be installed.

\section{Method and Tools}

Diagnostic and monitoring of the tomb case study cover a time span of 30 months. During

this period several analyzes and data collection were carried out:

- Monitoring of $\mathrm{T}$ and $\mathrm{RH}$ by means of sensors

- Monitoring of T and RH by means of a psychrometer

- Thermography scanning

- Sampling and measurement of the quantity of water present on the surfaces - Sampling and
quantification of the salt content
- Sampling and characterization of the biological degradation phenomena
Thermography and psychrometric measurements were performed on a seasonal basis. In
particular, the thermograms recaptured. wall and ceiling surfaces a to investigate any
variations due to the presence of water in the limestone tock bank due to rain, nattral sortrces

ariations due to the presence above garden that has been regularly watered for years. The seasonal acquisition

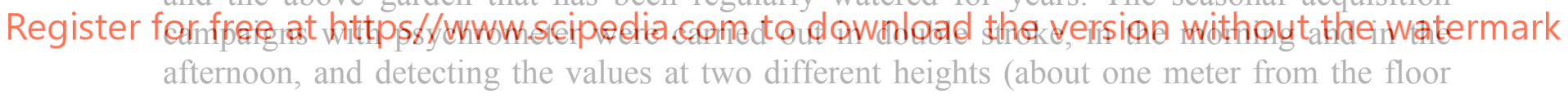

and near the ceiling). Finally, biological analyzes were performed for the characterization of some fungal formations that occurred only in certain periods and at specific external climatic conditions. All instrumental analyzes and investigations were carried out according to the regulatory standards contained in UNI 9252/88, UNI EN 16.714-1: 2016, UNI EN 13187: 2000.

\section{Results}

\subsection{Monitoring}

Prolonged monitoring over time has allowed researchers to build the so-called "historical climate" (Camuffo et al., 2015). The goal was to understand how and under which events the values of $\mathrm{T}$ and $\mathrm{RH}$ varied over time. The evaluation included the comparison with the environment data outside the tomb; a main the result was the identification of the time windows throughout the year in which the values of the microclimatic parameters were 
almost similar, leading to the consideration that any opening could not cause large imbalances and therefore potential risk situations for the interior decorated surfaces.

Moreover, the data processing made it possible to observe the distribution of the T and $\mathrm{RH}$ values within the room and the side niches: the greatest variations resulted near the entrance. In that area, the imbalance is due to the poor insulation of the door and the presence of a closing wall made of concrete and brick blocks (that was built years ago to close the tomb after the demolition of a part of the rocky bank). The variations in the temperature parameters, evident in the thermograms, are clearly due to the different thermal transmittance of the concrete and the brick compared to the limestone. The phenomenon of the temperature increase is also favored by the orientation of the entrance front to the south-west without any screen or shadowing object, therefore it is subject to solar radiation in the hottest hours of the day.

Today the conformation of the tomb has changed compared to the situation in which the psychrometric and thermographic shot were made. New sepulchral rooms and the original level of the floor, that over time had been covered, emerged during the archaeologicalexcavation carried out before the restoration works. Furthermore, the presence of archaeologists and restorers made it necessary to open the tomb with a much higher frequency than in the previous period. After the works inside have been completed, a new campaign of measurements with the psychrometer and thermographic acquisition is planned, to compare and analyse the changes that have taken place and formulate the appropriate design choices for the use of the site
The acquired data have shown that the distribution of temperatures is almost ho
throughout the whold year, with seasonal variations of around $2{ }^{\circ} \mathrm{C}$ and Relativ
between $90 \%$ and $100 \%$. The thermograms made it possible to high/ight so
anomalies near the entrance wall, for the reas ons described above, and in some p vaults of the side niches. This last phenomenon can be explained by a probable variation in

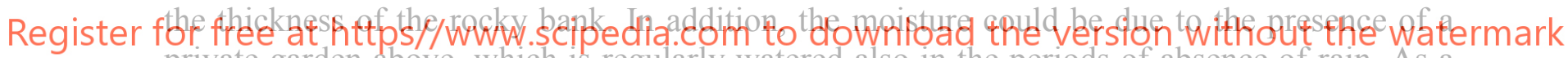
private garden above, which is regularly watered also in the periods of absence of rain. As a conclusion, it is probable that the concomitance of the presence of water in the ground practically constant and the reduced rock thickness make the infiltrations possible in some weak points.

As regards the laboratory analyzes carried out on the samples, it emerged that the quantity of water is particularly high, also confirming the humidity values detected with continuous monitoring and with the psychrometer. The analyzes however revealed a difference in the results between the samples taken near the entrance and those taken in the innermost parts. An explanation is that the ventilation conditions are different; in fact, the brick and block masonry and the uninsulated door felt higher ventilation than inside, thus favoring the surface evaporation of humidity. In natural conditions, the analysis of the internal values showed a variation of $0.5^{\circ} \mathrm{C}$ every ten days, approximately. After reporting the internal data compared to the external data, it emerged that the internal average values have variations that do not follow the external ones, as well as having a delay between the peaks (both maximum and minimum) of about two months compared to those detected externally. Instead, during the permanence of the archaeologists and restorers (December 2018) monitoring registered higher variations in temperature and more modest variations in humidity. 


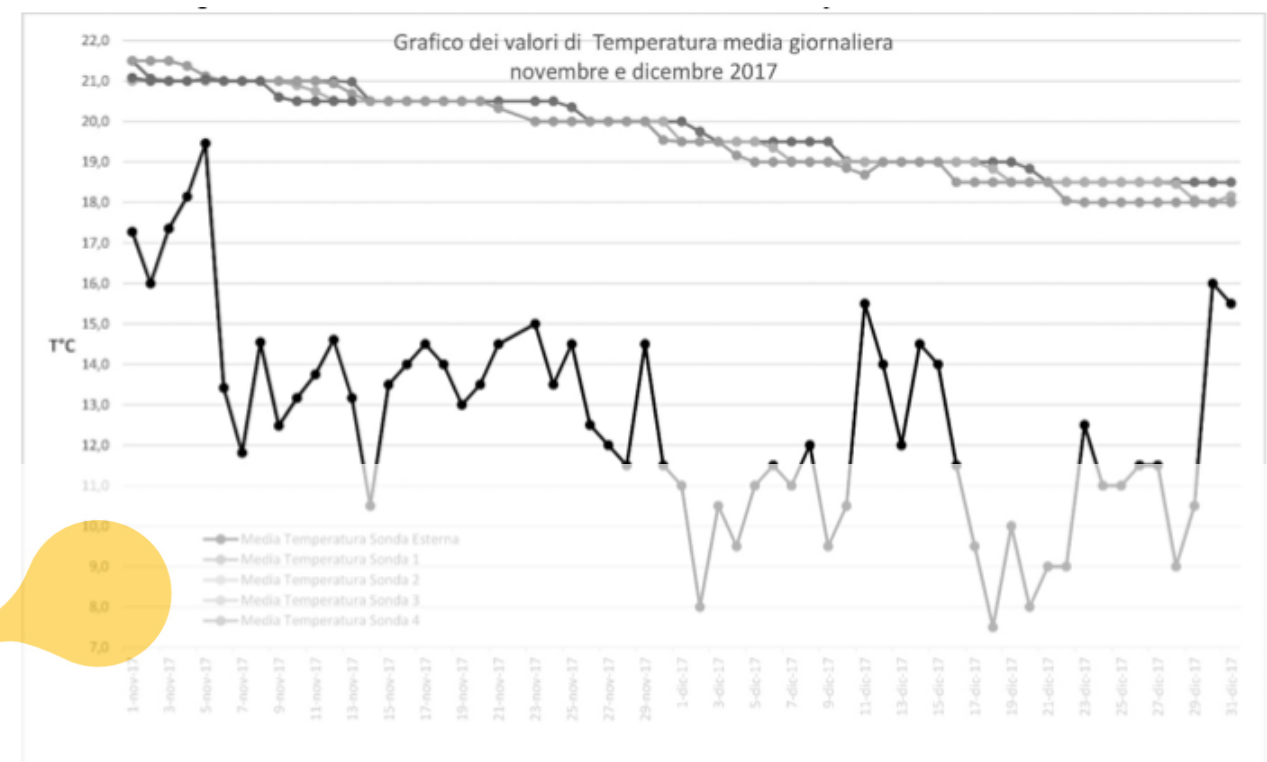

Figure 3. Graph of the dail
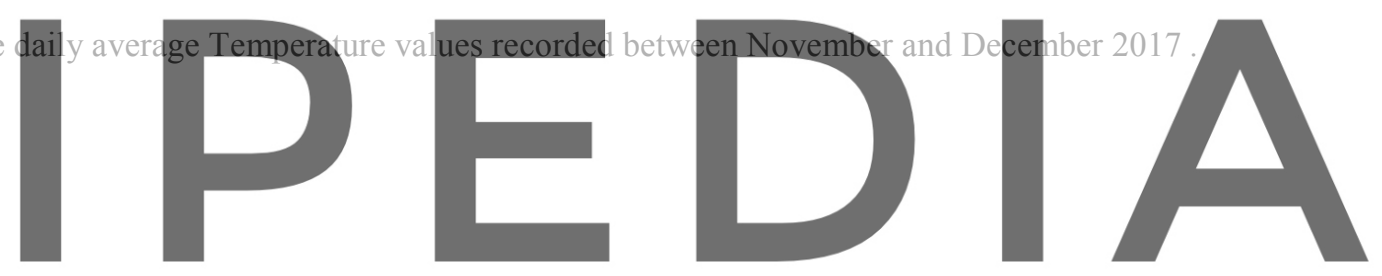

Register for free at http\$//www.scipedia.com to download the version without the watermark

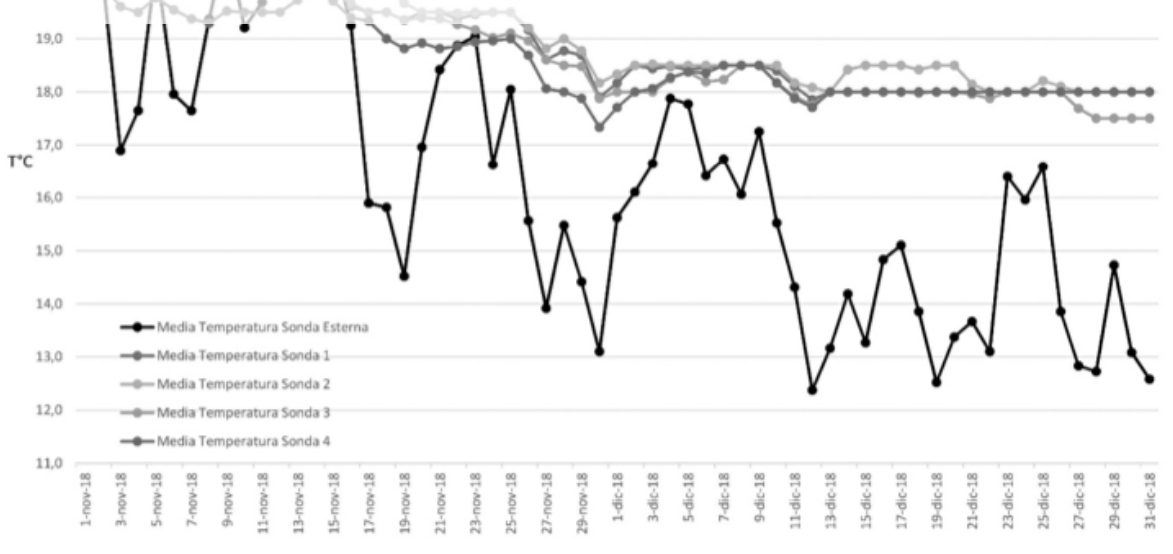

Figure 4. Graph of the daily average Temperature values recorded between November and December 2018. 


\subsection{Risk Factors}

Concerning the above and the results obtained from the diagnostics, the following risk factors have been identified:

- Variability of microclimatic values in different conditions

- Different conditions of exposure to the presence of water in the overlying layer (heterogeneity of shapes and dimensions of the rocky bank)

- Presence of people within the site

To the first point, in addition to the implementation of an air control system, the insertion of an inlet bush that acts as an isolation environment for the passage of people could be particularly effective to avoid instantaneous and frequent imbalances in ventilation and microclimatic values. This aspect is strictly connected to the good knowledge of the optimal valuesthat must be respected for the conservation of the surfaces.

To the second point, particular attention must be paid to the critical points when designing the systems which, due to the intrinsic construction characteristics, are more exposed to infiltrations.

Last aspect, the presence of people (meaning both visitors and other subjects who can access the rooms for various reasons), in addition to an accurate programme of times, frequency and maximum number of people admitted, the systems should guarantee the possibility of adjusting the air control according to the changes to maintain the optimal

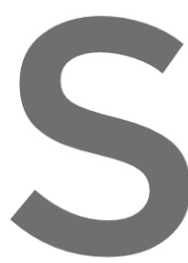

\section{Opening Versus Conservation? \\ The availability of scien \\ restorations with the investigation

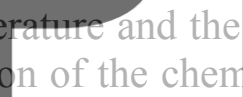

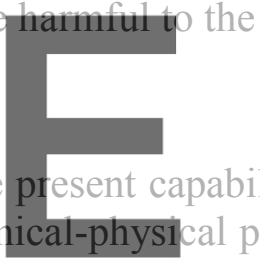
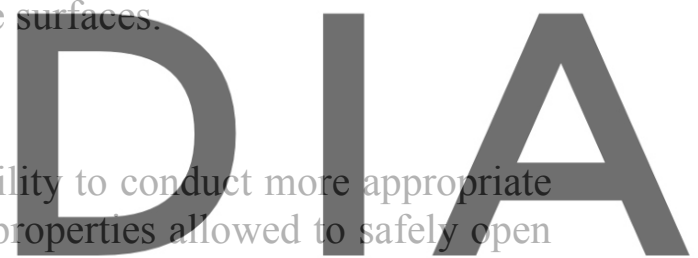

some tombs, through the study of air control and the management of the number of accesses.

Register for free athents / rsulted with god thermal inertialdue to the thickness and the quality af ermark the rocks. On the contrary this determines that the environments are particularly humid and,

with scarce possibility to reduce the humidity. The major thermal unbalances are located near the entrances and during their opening.

Therefore, to improve the durability of historic materials in such severe ambient conditions, the scientist and competent authorities took the choice to open only the tombs with more durable materials in open air and provide a consistent plan of conservation for periodic inspection and preventive activities.

Moreover, another analysis conclusion is that only few people at time can access. The installation of a narrow suspended path above the floor has been another help to reduce the passage of many visitors at the same time. The material of the walkway will be aesthetically compatible and waterproof to stand the high humidity and do not stain with rusty the underneath structure of the tomb. Special care has been devoted, design the entrance room, with the aim to create a double space isolate the microclimate from the external variation and guarantee an intermediate space for disables Although conservation goals seem to contrast the valorization ones, that include to visit the site, the experiences conducted in the last decades showed that is possible to combine such divergent issues by keeping under control the condition and constantly updating and revising the management plan. Especially in a time 
of possible variation in the climate, monitoring ambient conditions is crucial for any decision regarding the management of the fragile heritage exposed outside. The installation of visitor centers, in which it is possible to have virtual visits, watch videos, documentation and any multilevel shared knowledge, can highly decrease the pressure of real visitors. Nevertheless, opening the tombs remains a necessity that has to take into account and be possible also for technical purposes of the conservation itself. The design of the accessibility and its boundary remains one of the central focus of the conservation of archaeological sites, although sharing experiences and knowledge is far from any possible standardization of the solutions. What is possible, instead, is to share the best practices for acquiring data and monitoring in any phase of the long process of conservation, starting from the preliminary overview up to the maintenance and regular inspection after the restoration.

\section{ORCID}

Elisabetta Rosina: http://orcid.org/0000-0002-5137-1624

References

Blasco, M.F., Recuero, N., Aldas, J. and Garcia-Madariaga, J. (2018). Tourism sustainability in asrchaeological sites. Journal of Cultural Heritage Management and Sustainable Development, 8(3), 276-292.

Camuffo, D. and Bertolin, C. (2015). New insights and meaning of "historic climate" and reburial of

archaeological monuments. International colloquium and round table in "modern methods for the protection

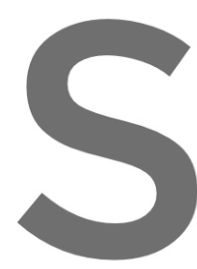
of newly uncovered climate and reburial of Cecchini, A. (2012). Le Kermes quaderni, Nardin

Della Torre, S. (2003). I Associati.

Della Torre, S. (2010).
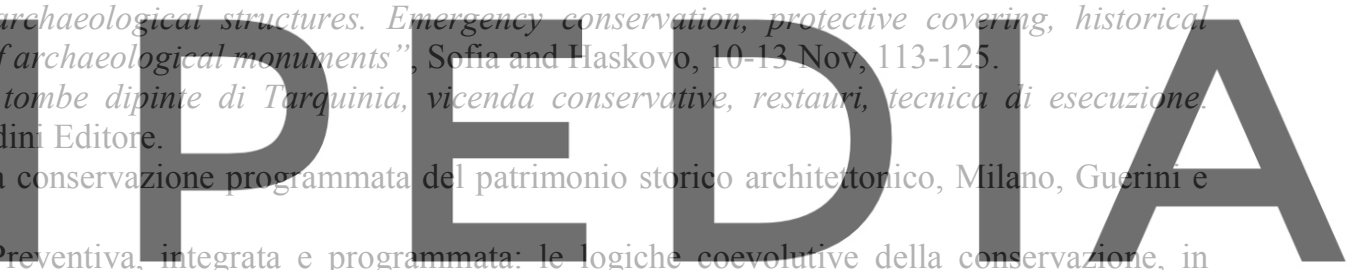

Pensare la prevenzione. Manufatti, Usi, Ambienti, Atti del convegno Scienza e Beni Culturali, Bressanone,

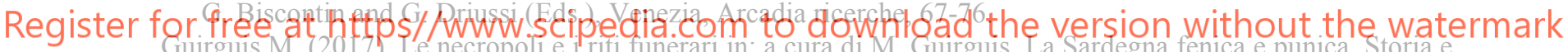
materiali, ed Ilisso, Nuoro.

Huisman, D.J., Borenhout, M., Smit, A., Van Os, B.J.H. and Manders, M. (2009). Preservation and monitoring of archaeological sites, Ch. 11, in Degradation of archaeological remains, D.J. Huisman ed., publ. Sdu, 177212.

Rosina, E. (2012). Non-destructive investigations: a case study of a convent in Lombardy (Italy), Annales, 2, 922

Rosina, E. and Suma, M. (2019). The complexity of conservation of outfitting, historic sites and buildings under everyday uses, Convegno Scienza e Beni Culturali, Bressanone.

Rosina, E., Zanelli, A., Beccarelli, P., Gargano, M. and Romoli, E. (2011). New procedures and Materials for Improving Protection of Archaeological área. Materials Evaluations, 69(8), 979-989.

Salvi, D., Sarigu, M., Pusceddu, V. and Zamora Lopez, J.A. (2016). Sepolture tardo puniche dal lotto 7 di Tuvixeddu: due storie di bambini mai nati e alcune osservazioni epigrafiche.

Salvi, D. (2005). Cagliari, Tuvixeddu - Quartucciu, Pill'e Matta. Notizie da due necropoli puniche, A.M. Arruda (ed.). Fenicios e punicos, por terra e mar, Actas do VI Congresso Internacional de Estudos Fenicios e Púnicos, Lisboa, 1100-1117.

Sanchez-Moral, S., Luque, S., Cuezva, V.S., Benavente, D., Laiz, L., Gonzalez, J.M. and Saiz-Jimenez, C. (2005). Deterioration of building materials in Roman catacombs: The influence of visitors, Science of the Total Environment, 349, 260-276. 
Standard for the procedures of gravimetric test UNI 11085/03 "Beni Culturali", Materiali lapidei naturali e artificiali. Determinazione del contenuto d'acqua: metodo ponderale.

Standard for the procedures of psicrometry and probes to monitor the microclimate UNI 10829 del 1999 Beni di interesse storico e artistico, Condizioni ambientali di conservazione, Misurazione ed analisi.

Stiglitz, A. (2014). Urbanistica di una necropoli: il caso di Tuvixeddu-Tuvumannu a Cagliari (Sardegna), ArcheoArte. Rivista elettronica di Archeologia e Arte, 3, 127-146.

Thompson, J. (2007). Conservation and management challenges in a public/private partnership for a large archaeological site (Herculaneum, Italy). Conservation and Management of Archaeological Sites, 8, 191-204.
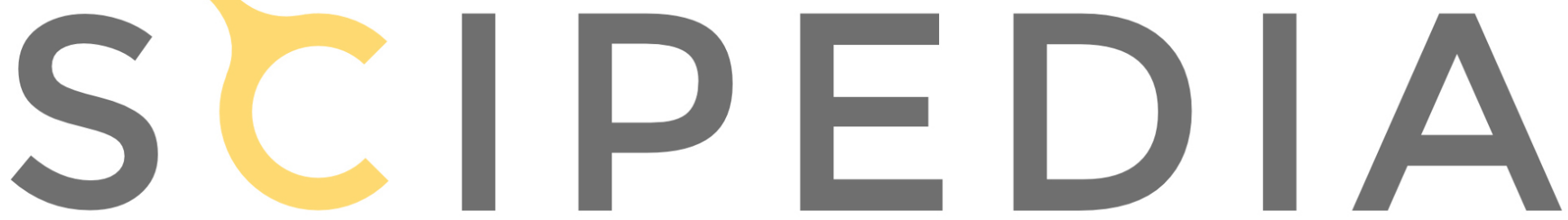